\title{
Exploration and Thinking on Real Time Reference Service in University Libraries
}

\author{
Xinbing Wang \\ Library \\ Tonghua Normal University \\ Tonghua, China, 134001
}

\author{
Xiaoshu Zhang \\ Library \\ Aviation University Air Force \\ Changchun, China
}

\begin{abstract}
Under broad environment of Web 2.0, digital reference service in university library gradually grows into a core business and takes booming internet as basic media of information, uses various instant messaging (IM) and its integration software, basically realizes full coverage of wireless network on campus through mobile terminals of high popularizing rate and achieves bidirectional interaction between readers in university and library. Under new situation, university library shall think about how to conform to development of the times and technology, provide real-time reference service for users in university whenever and wherever possible and let users simply and rapidly acquire information resources required in digital era.
\end{abstract}

Keywords-real-time reference service; university library; consultation service

\section{INTRODUCTION}

Digital reference service (DRS for short) emerges at the right moment under the condition of expanding various service functions of library to adapt to requirements of network environment and information at the new period and gradually grows into a core business of library service with rapid development of networking, informatization and digitalization. In 1984, the library of health sciences in University of Maryland of America took the lead in launching the project of the Electronic Access to Reference Services that uses e-mail to conduct reference service, in order to make uses can enjoy consultation service under the environment beyond physical space of the library and become pioneer of digital reference service. Digital reference service takes the internet as basic transmission medium of information and serves users with the help of good tools through ways of library website, E-mail, FAQ, BBS, QQ and microblog and satisfies users. [1] Various ways of digital reference service indeed bring convenience for readers, but problems still exist. Because of group characteristic of readers in university libraries, the way and habit of readers to get information have changed in essence. Most users are accustomed to getting the information required through network access, but their awareness in using reference service is weak. Although the users consult, because the number of reference consultants and working time are limited, it is impossible to timely reply questioning of readers on by one. It leads to the situation that readers have increasingly low requirements for reference service. If things continue this way, the use ratio of digital reference service will reduce gradually.
It becomes the striving direction of libraries including university library in digital era about how to provide real-time reference service for users whenever and wherever possible without limitation of time and space and let users simply and rapidly get information resources required.

\section{CURRENT SITUATION OF REAL-TIME REFERENCE SERVICE}

In middle and later 1990s, real-time reference service was born at the right moment. Compared with such virtual references as e-mail and table reference, real-time reference service receives a lot of attention of colleagues in library world because of its strong timeliness and novel means. It is generally accepted that traditional reference service has died away, and real-time reference service is the development direction. [2]

The coming of Web 2.0 age makes internet grow rapidly in thriving new pattern. Under broad environment of Web 2.0, technology and application represented by Blog, Wiki, SNS and RSS emphasize interactivity. Changes brought by this kind of technology let user get information in equal and individualized way and actively participate in it, make comments and suggestions to resources and service of library and have increasingly imperious demands to realize bidirectional interaction with library. [3] When information behavior of service object of library makes significant changes, with rapid development of technology of mobile internet, especially popularization of intelligent terminal and wireless network, looking for information and getting advice whenever and wherever possible becomes characteristic of users of library, especially users in university libraries. The popularizing rate of mobile phone and coverage degree of wireless network are relatively high. It strongly requires libraries to provide service whenever and wherever possible.

Nowadays, university libraries continuously explore on theory and practice and make some effective achievements.

\section{A. Traditional Real-Time Reference Service}

Represented by such ways as on-the-spot counseling, phone, E-mail, Web form, BBS and FAQ, traditional real-time consulting way completes the consultation process with users. At the present stage, university libraries can provide at least most of the services on the whole. 
1) On-site and telephone counseling service: Users can carry out barrier-free communication with consultation librarians through face-to-face way or telephone communication. The explanation and reply of all counseling message must be timely and effective. Users can revise and supplement question type, but it requires consultation librarians to have familiar and detailed understanding for related problems. In the majority situation, except for relatively simple routine problems, most counseling problems can get satisfactory answers through many times of communication.

2) E-mail and network form service: Using e-mail to carry out information service is a way of digital reference service conducted by libraries at home and abroad first, as well as the main way of digital reference service. It sets up an e-mail link on homepage of library or certain page. Users can send counseling problems through the link in the way of e-mail to corresponding consultation librarian, who will solve the problems in way of e-mail. Web form refers to the pattern that readers ask questions through filling in web form. Consultation librarians solve it in the form of e-mail. The process of service can be real-time or non-real-time. Consultation librarian has relatively bounteous feedback time.

3) BBS and message board service: BBS and message board service are also interactive service. Users can send problems to designated area through special webpage. Consultation librarians reply on the page. Problems and solutions on it can be seen by all users. All users can use existing solutions to solve problems of their own. Under the condition of not establishing virtual reference desk, it is a relatively common form, but this kind of interrogation reply system is not convenient for management. Besides, problems raised by users cannot get rapid and effective response. Therefore, now it mainly serves as auxiliary function of network-based reference platform.

4) FAQ service: FAQ service means that libraries edit problems may or actually raised by users into webpage according to ling-term reference service practice and investigation on users and establish link on specific location of library homepage for readers to inquire. It saves time of readers and reduces workload of consultation librarians. At present, libraries with good FAQ platform design provide browsing function and become relatively perfect in question classification and full-text search. It obviously exists in the form of small-scale database. This kind of improvement is a qualitative leap for service.

These service patterns are rapid, effective with smooth communication and relatively conform to habits of readers to get information from libraries at present, as well as meet demands of most readers to get information from libraries. Greatly limited by working time, number and quality of staffs, they cannot get reply to consulting during whole time from 24 to 7 .

\section{B. New Type Real-Time Reference Service}

1) Development of real-time reference service in university libraries of foreign countries: In June 2001, the first round-the-clock digital reference system, "Know it Now" project in America was launched by Ohio. After that, Illinois united with eight university library to conduct the project of Read for Reference Service, especially researching on how libraries to provide round-the-clock reference service. In the end of the same year, the National Information Standards Organization established committee that formulates standards of digital reference service. The introduction of the standard means real-time digital reference service becomes mature. With application and development of internet technology, popularization of joint reference service in global scale implemented by using the characteristic that time difference exists around the world can skillfully realize round-the-clock reference service. Take Cornell University and University of Washington as examples, the areas that they are located in have three hours of time difference. If carrying out joint digital reference service, they can provide users in the areas with digital reference service of more than three hours than average working hour. The facilitating agency launched by Library of Congress uses influence of its own, unites with libraries in areas of other countries through international cooperation. The difference of working time caused by time difference can provide possibility for international joint consultation service, continuously provide digital reference service for users and make "earth library" become possible as well as effectively solve the problem that reference service is limited by time and space.

2) Real-time reference service of domestic university library: Most new real-time reference service carried out by domestic universities depends on some relatively mature professional reference software that has been put into operation. IM (Instant Messaging) has become one of the main communication tools to carry out real-time reference service. IM and its integration software are basically free. Although it is commercial, the cost is very low. Most domestic university libraries adopt instant messaging service (such as QQ, MSN) or simple instant communication software of self-exploitation to carry out real-time reference service. In April 2009, Peking University Library formally launched IM reference service (MSN and QQ). Northeast Normal University Library and Tongji University Library also use IM to successively carry out reference service. [4] Tsinghua University Library developed real-time intelligent chatting robot "Xiao Tu" on the basis of A.L.I.C.E in 2011. "Xiao Tu" can provide various services such as questions and answers on knowledge of libraries, searching for library collections and Baidu Encyclopedia, self-learning and training, change object of real-time consultation that serves users into robot and overturn real-time consultation that consultation librarians must be serve at the background in traditional concept. Soon afterwards, Tsinghua University Library not only applies it on library homepage, but also launches it on social network of 
"Renren", which achieves good response. The highest daily number of users exceeds one thousand people. [5] It lets domestic university libraries see new direction on development prospect of real-time reference service.

In January 2011, Tencent Company launched communications software of "WeChat". Later on, university libraries successively develop WeChat public platform. According to rough statistics, by the end of March 2016, the number of university library that open $\mathrm{WeChat}$ public platform has reached one hundred. University libraries connect existing resources and service with WeChat, set up "My Library", booklist of library collection and database navigation and provide new real-time reference service platform for users to get information and consult whenever and wherever possible.

\section{PREDICAMENT OF REAL-TIME REFERENCE SER VICE}

Real-time reference service attracts great interest and attention of the library world. But after the initial period of freshness and excitation, real-time reference service becomes still gradually. After several years of practice, real-time reference service encounter bottleneck of development.

Real-time reference service of university libraries breaks through the limitation of time and space. Diversified service mode makes it extremely convenient for users in using reference service of libraries. It also greatly increases workload and difficulty in working of consultation librarians. The work of real-time reference service is an intensive work that needs brain power and manpower and requires libraries to scientifically and reasonably integrate personnel allocation. Because university libraries are limited by fund, personnel and technology, the situation in carrying out real-time reference service is different. Under many circumstances, libraries employ part-time digital reference librarians. Except for completing traditional duties and responsibilities, librarians are also responsible for real-time reference service. It is equivalent to extra job content. For consultation librarians, it is not small working strength. If things go on like this, the increase of work fatigue also makes the working efficiency of real-time reference service unsatisfactory. Under this situation, it is very difficult for single library to completely meet requirements of readers with huge difference in professional background. The consultation platforms of many university libraries are only open to campus of their own. Consultation librarians are only responsible for consultation system and readers of their own school. Even libraries in providing joint reference service have characteristics with small amount of joint consultation and low ratio in consultation work.

Besides, most university libraries have certain mistakes and deviation in selection of real-time reference software and cannot accurately position practical application. They cannot support operating costs and development technology to establish communication application software of their own just like Tsinghua University Library. After checking and testifying WeChat public accounts established by university libraries one by one, it is found that the information of some accounts is few and they become dead accounts without update, let alone providing real-time reference service.

\section{CONCLUSION}

It is the development tendency of university library in the future to let users in universities can enjoy any resource in libraries whenever and wherever possible. At present, most university libraries conduct real-time reference service to a certain extent. Some libraries that do not carry out the service also bring the construction of real-time reference service into agenda. The library world pays attention to how to better develop reference service in university libraries in our country. It is the development direction of university library in the future to refer to real-time reference service model of university libraries in developed countries, combine with practical situation of university libraries and users in our country, and reasonably bring all kinds of new concept and new technology into the field of real-time reference service as well as forge characteristic real-time reference consultation service system of libraries.

\section{REFERENCES}

[1] Wang Weixia. Innovation of Digital Reference Service [J], Information Studies: Theory and Application, 2006(6)

[2] Chen Li. Exploration on Real-time Reference Service in Library [J], Research on Library Science, 2005(10)

[3] Yao Wubin. Difficulties and Reflection on Real-time Virtual Reference Service [J], Sci-Tech Information Development and Economy, 2012(11)

[4] Liu Suqing. Let Virtual Reference Services Break through the Dilemma and Revive [J], Journal of Academic Libraries, 2009 (6)

[5] Yao Fei, Ji Lei, Zhang Chengyu, Chen Wu. New Trial on Real-time Virtual Reference Service-Intelligent Chatting Robot in Tsinghua University Library [J], New Technology of Library and Information Service, 2011(4)

[6] Li Jian. Analysis on Current Situation of Application of WeChat Public Platform in University Library [J], Journal of Library Science, 2004(6)

[7] Kuang Xueli. Research on Innovation Model of Digital Reference Service in University Library [M], Nanjing University, 2013. 